\title{
Revuelta feminista en Chile: cultura visual y performance $^{*}$
}

\author{
The feminist revolt in Chile: visual culture and performance
}

Bernardita Llanos $\mathbf{M}^{* *}$

\section{RESUMEN}

En este artículo se analiza la cultura visual que emerge en las performances de colectivos artísticos y políticos de mujeres universitarias durante la revuelta feminista chilena de mayo de 2018. Desde esta coyuntura, se propone una hipótesis: la performatividad de la revuelta proveyó el horizonte cultural que propició el estallido social de octubre de 2019. Para demostrar esta hipótesis, en primer lugar, se describen las bases epistemológicas de las performances de la revuelta de 2018; y, en segundo lugar, se escruta un caso particular: el proceso creativo que antecede el proyecto Yeguada Latinoamericana encabezado por Cheril Linett. Por último, se concluye que las redes forjadas en torno al trabajo de los colectivos de mujeres fueron claves para instalar preguntas feministas de largo aliento en la esfera pública del Chile actual.

\section{ABSTRACT}

In this paper, I analyze the visual culture that rises from the performances led by collectives of female college students during Chilean feminist strikes in 2018. From this scenario, I suggest a statement: the performativity of the feminist strikes illuminates a cultural horizon that made possible the social outburst from October 2019. To demonstrate this statement, firstly, I reveal the theoretical basis of feminist performances. And secondly, I examine the creative process that lay under one of the most significant feminist performances: YL, by Cheril Linett. Lastly, I conKeywords: Chilean

Palabras clave: revuelta feminista chilena de 2018, estallido social chileno de octubre de 2019, colectivos artísticos feministas chilenos, performatividad, activismo feminista. feminist strikes (2018), Chilean social outburst (2019), collectives of female college students, performativity, feminist activism.

\footnotetext{
* Agradezco a Brooklyn College, CUNY su apoyo a este artículo

** Chilena/americana. PhD en Literatura y Lingüística Hispánica y Luso Brasileras por la Universidad de Minnesota . Profesora de Género y Literatura Latinoamericana en el Departamento de Lenguas y Literaturas Modernas de Brooklyn College, CUNY, Brooklyn, Nueva York, Estados Unidos. Bllanos@brooklyn.cuny.edu
} 
Revuelta feminista en Chile: cultura visual y performance | Llanos

clude that the feminist collectives straightened during the 2018's strikes were fundamental to install a set of political demands shaped by the (new) waves of feminism in a changing contemporary Chile. 


\section{Mayo, 2018}

La revuelta feminista de 2018 se convirtió de uno de los fenómenos sociales y culturales más significativos del pasado reciente, al punto que dio origen a nuevas y diversas expresiones estéticas de carácter deliberadamente feministas en las que predominaban los llamados a desmantelar el sistema neoliberal y, a fin de cuentas, a cambiarlo todo. En cada una de estas expresiones, encontramos planteamientos provenientes del feminismo en diversas y múltiples vertientes: desde el feminismo de la diferencia y la interseccionalidad, hasta el de la disidencia sexual y queer, pasando por el feminismo comunitario y el feminismo popular, entre otros. Dentro este conjunto de líneas divergentes, la lucha por la emancipación y la igualdad de las mujeres, las disidencias sexuales y las personas no binarias aparece como uno de los objetivos políticos cruciales. La necesidad de construir una sociedad más justa y equitativa supone, en este contexto transformador, la crítica a la hegemonía de la élite social y política que propicia la conservación de un sistema patriarcal neoliberal que sigue marginalizando a las mayorías. $\mathrm{Y}$, tal como insisten las mujeres de la revuelta de mayo, este sistema, además de marginalizar, continúa usufructuando y explotando los cuerpos subalternos y sus fuerzas de trabajo tanto productivo como reproductivo. Así, el reclamo y la unidad en la diferencia de los géneros y las sexualidades se hace transversal en esta revuelta. Con ello, su movimiento rompe el contrato social y deconstruye todas las estructuras y los valores dominantes en torno a la familia, la heteronormatividad y el Estado - cae, así, la trilogía conceptual de la educación confesional para mujeres que permeó la sociedad chilena en el primer tercio del siglo XX: dios, patria y hogar-.

En esta coyuntura, este artículo se propone analizar algunos ejemplos de estas manifestaciones culturales callejeras surgidas durante el mayo feminista, manifestaciones que inauguran una nueva cultura visual mediante grafitis, afiches y paste ups. En el campo de la performance de artistas y colectivos de la disidencia se destaca sobre todo Cheril Linett. Las performances han sido parte integral del movimiento feminista y "son prácticas, modos de conocer el mundo que desafían tanto a quienes observan como a quienes las realizan", creando nuevos marcos de significación que deconstruyen sistemas identitarios y de privilegios que van desde el racismo hasta el heterosexismo, la homo- 
fobia y la transfobia mediante prácticas culturales corporizadas - a decir de Silvia Lamadrid (16)—.

\section{De la sala a la calle}

Antes de emprender el análisis, huelga decir que a partir del mayo feminista de 2018, observamos que estética y política se ligan para construir formas de intervención que abandonan las instituciones tradicionales y convierten el espacio público y, en particular, la calle, en tribuna donde se reclama, se grita y donde también las jóvenes estudiantes universitarias descubren sus pechos, desplazando con ello las simbologías del cuerpo femenino en cuanto objeto sexual y maternal; con su intervención, las jóvenes hacen visible la afirmación de su derecho inalienable a la autonomía. Justamente, en la marcha que convocan las estudiantes, se politizan mediante un ritual en el que al torso desnudo y al puño en alto se suman las gorras o capuchas rojas y moradas cuidadosamente ornamentadas - muchas decoradas con mostacillas y finas cuentas de múltiples colores-. La denuncia del acoso, el abuso sexual y la violencia de género en todas sus formas constituyen el reclamo feminista estudiantil el cual, desde el cuerpo, descoloca y cuestiona las formas tradicionales de la política, según advierte Luna Follegati (78)

El movimiento feminista y su revuelta desde los centros de estudios superior ha sido uno de los pilares más importantes en el levantamiento ciudadano del estallido del 2019, ya que ha ampliado su convocatoria a grandes sectores de la sociedad chilena que han experimentado la precarización, la falta de derechos y el abuso (por ejemplo, miembros del pueblo mapuche, inmigrantes del sur global, comunidades afrodescendientes, personas trans, individuos jubilados o pobladoras de campamentos, entre otros). Como afirma Lamadrid, en la última década, desde los movimientos sociales (el movimiento estudiantil, el tsunami feminista, las disidencias sexuales y los movimientos territoriales, entre otros), han surgido nuevos actores y demandas en el espacio público; juntos, actores y demandas han reactivado la acción colectiva en Chile y, de paso, han cimentado el territorio que enseguida fue escenario del estallido social de octubre de 2019 (Lamadrid 83).

Las tomas de centros de enseñanza superior y secundarios emprendidas por alumnas feministas junto con sus protestas callejeras 
dan origen a una nueva cultura visual de signo emancipador y rebelde contra el orden imperante, cuyas estructuras patriarcales y sexistas se denuncian y critican abierta y frontalmente en esta nueva ola feminista que algunos han denominado la cuarta ola. Las demandas del mayo feminista, por una parte, expresan la crisis de representación de la democracia chilena y, por otra, las extienden y socializan a través de los medios sociales, contribuyendo a los debates de hoy acerca de la democracia en el país (Reyes-Housholder ctd. en Lamadrid 12-13).

Las expresiones estéticas plantean un cambio de paradigma en el cual el cuerpo femenino aparece como un territorio desde el que se emprende la lucha por la igualdad y la interpelación por el lugar de lo femenino y masculino, principalmente a través de las representaciones del arte y del activismo (Giunta 13). La agencia de las mujeres es otro de los aspectos sobresalientes en la producción visual y performática de este movimiento que irrumpe con fuerza subversiva y radical. Como señala la filósofa Olga Grau (2018), este acontecimiento inusitado e inédito en la sociedad chilena convierte a las jóvenes en sujetos/ as políticas, insistiendo en el derecho del propio cuerpo a no ser usado ni violentado (Grau 91-93).

El arte feminista, en tanto, aborda su accionar desde "el activismo resistiendo al neoliberalismo, interpelando la vida cotidiana y la pública, generando denuncia, conciencia y cambio" (Flores 79). Se trata de un arte eminentemente desestructurador que se rebela contra el abuso, la subordinación y la opresión de las mujeres y las disidencias, convirtiendo sus experiencias en dispositivos simbólicos que desafían y desmontan la ideología patriarcal y un sistema económico de explotación planetaria. Sus diversas manifestaciones pueden verse en la revuelta de octubre de 2019 y en las imágenes que, tras ella, cubren las paredes de Santiago y de otras ciudades del país - en especial, sus plazas de armas y sus monumentos que tributan a los héroes de las épicas coloniales o republicanas. La intervención de estas figuras patrias con signos y mensajes decoloniales y feministas es otra impronta que se repite a nivel nacional, que cuestiona la historia oficial patriarcal y sus efemérides masculinas.

El activismo feminista forma parte integral del malestar social que atraviesa la sociedad chilena actual y que según algunos sociólogos es parte del proceso de modernización neoliberal y de los pactos de la 
transición. En este sentido, la lucha feminista y de las mujeres se entiende como una forma de vanguardia que sacude los consensos y los silencios de los acuerdos transicionales. La mayor integración de las mujeres a la esfera pública a través de la educación y el trabajo se ha dado mediante la preservación de valores de género conservadores en el espacio privado y con derechos escasos y precarios. La integración educacional masiva de jóvenes a nivel terciario se ve reflejada en el movimiento estudiantil y sus protestas del 2006 y 2011, donde se potencia el feminismo desde su interior (Lamadrid 12-13). También el resurgimiento feminista se vincula con la historia del feminismo en el país y las políticas de la igualdad de oportunidades gubernamentales y con la obstinada presencia de las feministas autónomas en "la recomposición de la acción colectiva" (13), la diversidad de experiencias y organizaciones hoy día presentes en las movilizaciones.

Este resurgimiento feminista, por una parte, dinamiza al movimiento estudiantil a nivel local y, por otra, coincide y se conecta con la emergencia de otros movimientos feministas regionales y globales como Ni una menos (que surge en el 2015 en Argentina contra la violencia machista y el feminicidio) y el \#MeToo (que estalla en Estados Unidos contra el abuso sexual de hombres influyentes, particularmente en el mundo del cine, la televisión y las comunicaciones).

\section{La revuelta feminista y su impacto}

Descrito el contexto la premisa de este trabajo es: el estallido social no puede explicarse sin el mayo feminista del 2018, que representa uno de sus antecedentes históricos y el cual movilizó a gran parte del estudiantado universitario. El movimiento feminista gatilló una multiplicidad de protestas, marchas, ocupaciones y movilizaciones que se originaron en la Universidad Austral de Valdivia en abril del 2018 y se expandieron velozmente a regiones y diversas universidades del país. Las tomas de los recintos junto con las denuncias contra los abusos y acosos sexuales de profesores varones se sucedieron. La figura de la estudiante de derecho Sofía Brito y el docente de la Facultad de Derecho de la Universidad de Chile, Carlos Carmona ${ }^{1}$, representa uno de

1 Téngase presente que Carmona era, además de prestigioso académico en el campo del derecho, expresidente del Tribunal Constitucional. Para mayores detalles, véase 
los momento más álgidos de la escala del abuso poder y el acoso sexual dentro de un recinto de educación superior (Miranda Leiva y Roque López 60). El apoyo y protestas de las estudiantes frente a la denuncia de Sofía Brito, devela la acción colectiva como una forma efectiva de enfrentar las estructuras de poder patriarcal y exigir el cambio como un derecho ciudadano y de género.

La ocupación de la Casa Central de la Pontificia Universidad Católica de Chile fue otro hito de la protesta que quedó catapultado en la imagen de la joven estudiante con su capucha roja, los pechos al descubierto mientras está parada sobre la estatua del Papa Juan Pablo II. La imagen condensa y simboliza el nuevo poder feminista estudiantil y el destronamiento de la autoridad masculina. González (ctd. en Lamadrid 15) propone entender al mayo feminista chileno a partir del cruce entre tres elementos claves:

- el momento de efervescencia feminista internacional y de renacimiento de un feminismo militante;

- la latente y creciente organización del campo político feminista chileno - en su fragmentación y heterogeneidad- en el tejido social en la última década;

- su entrecruzamiento con el movimiento estudiantil, probablemente el más relevante actor social reivindicativo y transformador desde la transición democrática.

La rebelión feminista reconoce su "condición desigual y excluyente", posicionándose con la demanda de una educación no sexista que unifica al movimiento en su deseo por transformar las estructuras sociales, simbólicas y culturales "que perpetúan la subordinación de las personas" por su diferencia, género y orientación sexual como sostiene Follegati $(77,79)$. El feminismo, por otra parte, ha servido como punta de lanza rizomática para aglutinar nuevas y diversas agrupaciones a través del país hasta desembocar en el estallido de octubre de 2019, donde convergen múltiples y diversos sujetos. Fruto del mayo feminista es la Coordinadora $8 \mathrm{M}$, una de las organizaciones de mayor convocatoria que aúna una gran multiplicidad de colectivos feministas a

en CIPER la investigación periodística "Episodios inéditos del sumario por acoso sexual contra el profesor Carlos Carmona” de Gabriela Pizarro. 
partir de los Encuentros Plurinacionales, asambleas y manifestaciones. Su poder y efectividad para articular y aglutinar la acción colectiva de múltiples y diversas organizaciones y grupos a través del país da muestra de su impacto social y político ${ }^{2}$.

Los "nuevos imaginarios feministas pueblan las subjetividades actuales" que fueron testigos de paros, tomas, asambleas y marchas masivas contra el patriarcado, el abuso sexual y de poder en las universidades y el acoso callejero al son de consignas como "[a]coso, abuso también violaciones/eso es lo que callan las instituciones", o "Y cómo, y cómo, y cómo es la huevá/ nos matan y nos violan/ y nadie hace ná" (Oyarzún 99, 101). Estos mensajes evidencian el milenario atropello patriarcal como el hecho de que la violencia histórica hacia las mujeres atraviesa la sociedad en todos sus ámbitos desde la pedagogía y los claustros hasta el trabajo, la familia y el lenguaje, como señala la crítica Kemy Oyarzún (103). La socióloga Lara Ponce (ctd. en Lamadrid 15) llama a este feminismo la cuarta ola, pues asume demandas de la segunda ola por una mayor libertad sexual y la legalización del aborto, además de visibilizar el mundo privado. También toma reivindicaciones de la tercera ola, la que visibiliza la diversidad de las identidades. Lo propio de esta cuarta ola sería la crítica al acoso sexual y la violencia contra la mujer que conecta contextos locales y globales mediante la organización y el uso de plataformas digitales. El movimiento feminista actual recupera memorias y tradiciones de los movimientos de los 80, incorporando esos relatos y conversaciones a su repertorio.

La filósofa Alejandra Castillo, por su parte, habla de la vorágine feminista que tuvo lugar durante dos meses e hizo escuchar su rotundo "No más" a los abusos del Estado autoritario y patriarcal" (Castillo 36). El impacto del mayo feminista del 2018 sobre la revuelta social ha sido notado por escritoras e intelectuales, entre ellas Diamela Eltit y Rita Segato (2021), quienes han planteado que la movilización social y la rebelión contra todas las formas de abuso patriarcal y neoliberal convergieron en este momento de rebelión gatillado por el mayo feminista, mostrando el ímpetu descolonizador de esta nueva insurgencia masiva.

2 Para una introducción al trabajo de la coordinadora, véase su presentación: http:// cf8m.cl/quienes-somos/. 
De ahí que en este sentido pueda hablarse de una nueva etapa feminista en la lucha contra un terrorismo sexual contra las mujeres al decir de Carole Sheffield (2007), cuya denuncia la encontramos en las consignas "Patriarcado y capital/es alianza criminal o mujeres contra la violencia/mujeres contra el capital/mujeres contra el machismo/contra el terrorismo neoliberal" (111). Los lazos entre capitalismo neoliberal y violencia patriarcal se expresan por primera vez abierta y claramente en la calle y en las universidades (Oyarzún 104). Se exponen así los pactos de una masculinidad colonizada históricamente y que desde la conquista hasta hoy negocia, apropia y expropia cuerpos feminizados y racializados junto con territorios y recursos. Frente al expolio del Estado neoliberal, las feministas sostienen el autocuidado y el tiempo para sí y los otros como una forma de resistencia al sistema (108).

María Iris Flores (2018), historiadora del arte y curadora feminista comenta: "El movimiento feminista ha permitido difundir que existe un sistema que nos sitúa en un lugar diferente al de los hombres, que se nos castiga de múltiples maneras por ser mujeres, y que somos nosotras . . . desde la organización y el compañerismo quienes podemos cambiar paulatinamente esta realidad" (81). La unión transversal entre mujeres de diversos orígenes, edades, etnicidades y clases sociales constituye las obras de la rebelión feminista; imágenes que se repiten a través de carteles y afiches, banderas y lemas en la ciudad y en muchas de las protestas de los viernes en la Plaza de la Dignidad. El fin del patriarcado y el nacimiento de otra era en la cual las mujeres, las disidencias sexuales y los pueblos originarios junto con otras alteridades, son protagonistas de una nueva gesta emancipadora. El deseo y la utopía renacen en las diversas expresiones visuales y artísticas del estallido social donde la impronta feminista es diversa y múltiple. Frente a la violencia y represión de las fuerzas policíacas, aparecen las jóvenes encapuchadas de la primera fila, cuyas capuchas antigas recuerdan al mayo feminista y la influencia del colectivo de arte ruso Pussy Riot en su embestida contra el autoritarismo patriarcal. El feminismo estudiantil demanda una democracia que incluya el país, la casa y la cama, mostrando que involucra la vida entera por lo que pone en cuestión tanto la representación política como el alcance de las política sociales de un Estado neoliberal que limita la democracia y es subsidiario, por lo que no puede procesar estas demandas sociales (Lamadrid 19). 


\section{Por un arte colectivo}

En un paste up anónimo en las paredes de la Torre Telefónica en la Plaza de la Dignidad, se observa una imagen-texto en la que hay una mujer de luto con un ojo sangrando - con la forma del mapa de Chile- y el otro ojo lleva un parche que alude a los mutilados del estallido. En el lado derecho e izquierdo de la figura aparece el mensaje: "NOS PODRÁN QUITAR LOS OJOS. PERO JAMÁS NOS QUITARÁN NUESTRA VOZ", señalando las violaciones a los DD. HH. y afirmando la lucha colectiva (Domingo 62). Detrás de la mujer está el mar y un cielo gris que enmarcan el sentido de vida y muerte de la insurgencia.

Por su parte, el colectivo feminista Musa Mosaico, realizó un mosaico con la cara del activista homosexual y cronista Pedro Lemebel (1952-2015), cuya imagen espectral ha aparecido tras el estallido en diversos formatos y dispositivos. El mural está en la calle Nataniel con Tarapacá y ha sido destruido en diversas oportunidades, al igual que otro con el perro Negro Matapacos, ícono del levantamiento social y que se ubica en la fachada del Centro Cultural Gabriela Mistral, GAM, también parcialmente destruido. El objetivo del colectivo es "rendirle homenaje" a conocidas figuras de la contracultura, como Pedro Lemebel, Violeta Parra, Andrés Pérez e Hija de Perra, entre otras. Para la artista Isabel González, miembra del colectivo, que le quiten los ojos al mosaico de Lemebel es una referencia ideológica clara contra lo que este artista representa como voz proletaria del arte y la disidencia sexual (Espinoza s.p.).

El colectivo feminista de Valparaíso, Lastesis representa una de las expresiones ejemplares en el campo de la performance y de la alianza entre feminismo y artivismo donde las artistas hacen un llamado abierto a participar a cualquier interesado/a. El artisvismo es una práctica artística que combina el activismo con el arte y que ha sido utilizada principalmente en el cine, la música, el arte callejero y la performance como una forma de crear consciencia y movilizar la acción social hacia el cambio. Las performances masivas de Lastesis muestran coreografías donde el movimiento corporal y el canto de mensajes antipatriarcales son cruciales en una estética democratizadora. Su famoso y viralizado performance "Un violador en tu camino" es considerado hoy en día un himno feminista que denuncia las acciones abusivas del Estado, el capitalismo y el machismo que daña y asesina. Su circula- 
ción y realización en múltiples idiomas y diversas partes del mundo por mujeres y disidencias ha servido para resaltar la lucha feminista por una democracia diversa y equitativa en sociedades autoritarias y patriarcales. Por otro lado, el estrecho vínculo entre Lastesis y las Pussy Riots de Rusia subraya la creación de redes feministas transnacionales en las que el trabajo conjunto se basa en la solidaridad.

$\mathrm{Al}$ respecto, uno de los últimos videos de Lastesis en internet fue prohibido en Chile por orden judicial, debido a los cargos que levantó la institución de Carabineros - la letra denunciaba el abuso de poder y las violaciones de los derechos humanos por parte de la fuerza policial-: "Nos persiguen, bloquean las salidas de nuestras casas, provocan, se infiltran como protestantes y comienzan a quemarlo todo. Desfilan armados por nuestras calles. Lanzan gases, golpean, torturan, violan, destruyen, nos ciegan. El gobierno no escucha y renueva las armas de la policía. Fuego a los pacos, fuego a la yuta". Fueron estas palabras en las que se basó Carabineros para interponer una denuncia contra el grupo por atentado contra la autoridad e instigar a la violencia. Así comenzó un libelo judicial del que Lastesis fueron finalmente sobreseídas ${ }^{3}$. En este contexto, las Pussy Riots colaboraron con el colectivo y subieron a su cuenta en YouTube el video censurado en Chile, para que siguiera circulando libremente. Esta forma de evadir la censura de las autoridades de un país a través de una red feminista con otras artistas, muestra las estrategias del feminismo actual y, en especial, las formas del artivismo y su efectividad en el uso de las plataformas digitales y los medios sociales.

El siguiente proyecto feminista que quisiera destacar es Yeguada Latinoamericana, que convoca la artista visual y performormera, Cheril Linett (2020). La Yeguada ha realizado numerosas acciones y generado múltiples reacciones desde su irrupción en una sesión en pleno en el Congreso durante la revuelta feminista del 2018, defendiendo el derecho al aborto con un lienzo que decía "Abortistas". Linett afirmó al respecto: "sacamos nuestras colas de bestias mutantes, de yeguas" no solo para manifestarse a favor del aborto, sino para "abortar la justicia

3 Para mayor información, consultar https://www.soychile.cl/Valparaiso/Socie$\mathrm{dad} / 2020 / 06 / 18 / 659831 / N u e v o-v i d e o-d e-L a s-T e s i s-o r i g i n o-d e n u n c i a-a n t e-F i s c a l i a-$ por-atentado-contra-la-autoridad.aspx 
patriarcal y las decisiones que están tomando ahí adentro, que quieren decidir sobre nuestros cuerpos y más encima, hombres" ("La protesta feminista...”). Linett ha descrito su propuesta autoral en la Yeguada Latinoamericana como un llamado a la acción directa y cómplice donde la performance de los feminismos de la disidencia buscan nuevos soportes e imaginarios de protesta en la revuelta callejera (87). La exploración corporal tiene su origen en Bestia lúbrica con sus primeras acciones en la calle y mediante el uso de una cola como prótesis anal ${ }^{4}$. La idea de una manada de yeguas en la calle opera en oposición a la caballería de Carabineros, quienes utilizan los caballos en sus operaciones para amedrentar a la ciudadanía que protesta, además de arrojarle gas pimienta, gases lacrimógenos y golpearla (93). El abuso especista que hace la fuerza del orden público sobre los caballos también es denunciado por la Yeguada, que se opone a la utilización equina como fuerza de carga esclavizada tal como al de los seres humanos en posición subalterna. De ahí que establezca una relación y conexión entre el cuerpo de la yegua y la mujer y otros cuerpos feminizados subalternizados y explotados (93).

Linett ha dirigido y convocado a mujeres y disidencias sexuales a participar en acciones en el espacio público desde el 2017 con el propósito de "subvertir, criticar y desafiar los regímenes clasistas, patriarcales, coloniales y especistas, por medio de la performance como lenguaje, práctica y expresión artística" (89-90). En las performances de la Yeguada la pregunta sobre qué es ser mujer se da a la par del llamado a la desobediencia a las instituciones del orden: Iglesia, Carabineros, familia, Estado y patria (90). El rechazo a la heteronormatividad como sistema de privilegio y exclusión permite la integración de mujeres trans, trabajadoras sexuales, travestis, transformistas y personas no binarias, reconociéndose como "sujetas insumisas" frente a las posiciones y definiciones hegemónicas que las han signado como inferiores, "mutilando su animalidad e instintos" (91). El deseo aquí se entiende como fluyo indisciplinado y movilizador en la línea de Deleuze y Guattari, volviendo el cuerpo una máquina deseante contra el patriarcado y el capital (94).

4 La prótesis desnaturaliza y modifica la forma humana que Linett toma de la estética sadomasoquista. 
Entre las performances realizadas contra Carabineros, aparece "Orden y Patria”, acción frente a un cuartel de la policía en el centro de Santiago, donde el grupo enseñaba las nalgas con la cola, parapetadas en una barricada de la que salían humos negros. El registro fotográfico capta a un militar armado con metralleta delante de las mujeres como presagio de la fuerza y violencia que utilizará el cuerpo policial contra los y las manifestantes en las marchas. Esta performance también podría leerse como una acción colectiva por la paz y el desarme de las fuerzas del orden público que aparecen armadas en el registro, contraviniendo la noción de servicio a la ciudadanía y democracia que las debe definir.

"Estado de Rebeldía" es otra performance que encarna la revuelta feminista en el color fucsia de la pintada del mensaje en la calle. Las performeras aparecen de boca en el suelo a un costado de la calle Alameda, interrumpiendo el tránsito, con los vestidos subidos hasta la cintura, las colas y las nalgas al aire. La protesta feminista es evidente en la posición de los cuerpos y el estar semidesnudas, sugiriendo múltiples sentidos sexuales y culturales sobre el cuerpo femenino, el desnudo en público, la moral machista y la libertad ciudadana, mientras los transeúntes se detienen a tomar fotos, aplaudir o condenar. El cuerpo aquí se exhibe substrayendo su sexualización a la mirada patriarcal y en analogía con la yegua y sus diversos significados peyorativos. Estas performances se realizaron en 2019 en el mes de octubre, un mes antes de "Un violador en tu camino" de Lastesis, haciendo de la performance feminista una de las expresiones artísticas predominantes a lo largo de varios meses de protestas hasta la llegada del COVID-19 y el confinamiento.

El cuerpo es uno de los temas y dispositivos con los que Yeguada Latinoamericana trabaja, siguiendo algunas de las ideas del artista visual y cronista Pedro Lemebel (1952-2015) acerca de la disidencia sexual proletaria como lugar de descolonización corporal y cultural. La Yeguada deconstruye el poder heteronormativo de las instituciones y el dominio sobre el cuerpo que tiene la cultura patriarcal. El trabajo de la performance tiene como eje los cuerpos queer y subalternos y su metamorfosis hasta borrar las fronteras entre lo humano y lo animal mediante el dispositivo de la cola equina. Las respuestas viscerales que muchas veces provocan en el público callejero, van desde la rabia 
e insulto entre los detractores y la fascinación de seguidores en vivo y en los medios sociales, lo que muestra el impacto de la Yeguada en la sociedad chilena y la moral dominante ${ }^{5}$. Sus acciones se enmarcan en presupuestos feministas de la diferencia queer, donde el cuerpo se concibe como un territorio en disputa con el orden social y el sistema heteronormativo, racializado y de clase imperante en la sociedad neoliberal chilena, haciendo del potencial disruptor del cuerpo una suerte de explosivo simbólico. En la Yeguada Latinoamericana existe un sentido de urgencia y confrontación, ya que se plantea como una guerrilla urbana, cuyo artivismo recuerda a las Guerrilla Girls y su lucha contra el sexismo y racismo en el mundo del arte ${ }^{6}$. La Yeguada tiene el objetivo de liberar el cuerpo del entramado heteronormativo, del legado dictatorial y de la violencia político-sexual que persiste hoy en día contra las mujeres, las disidencias sexuales, los cuerpos racializados y los migrantes (Linett 101).

La eclosión de imágenes, grafitis, poemas y performances configuran el imaginario visual de Chile hoy en sus muros. Esta proliferación de imágenes generadas por el levantamiento masivo del estallido social de octubre 2019 no puede comprenderse sin considerar la lucha y organización del movimiento feminista actual "cuyo sentido ha sido la negación", un NO rotundo a la precarización de la vida y a los abusos acumulados de una transición pactada (Carrillo Vidal y Manzi Araneda 175-177). El mayo feminista del 2018 y la huelga general feminista del $8 \mathrm{M}$ son parte de este movimiento social que defiende otra forma de vida.

El arte en la calle cumple hoy un propósito social que dialoga y se nutre de los sucesos sociales y políticos que han llevado a la Asamblea Constituyente, donde sus miembros han sido elegidos por decisión popular de espalda a los partidos tradicionales y la lógica electoralista. Los grafitis anónimos como las performances de Lastesis y de la Yeguada Latinoamericana forman parte del repertorio feminista y su fuerza

$5 \quad$ Entrevista no publicada de la autora con Cheril Linett, noviembre de 2019.

6 Este grupo feminista de artistas mujeres anónimas en el Nueva York de mediados de los 80 dejó su impronta en las formas en que expusieron la discriminación de género y racial en apariciones públicas, libros y afiches. Su distintivo era que llevaban máscaras con caras de gorilas y usaban seudónimos referentes a artistas muertas. Privilegiaban lo colectivo por encima de sus propias individualidades. 
emancipadora, la que demanda terminar con una sociedad mercantilista dominada por la deuda y la precariedad.

\section{Referencias bibliográficas}

Carrillo Vidal, Alondra y Javiera Manzi Araneda. "Lo constituyente, lo destituyente y la imaginación política feminista”. Por una Constitución feminista. Ed. Sofía Esther Brito. Santiago, Pez Espiral, 2020, pp. 163-184. Impreso.

Castillo, Alejandra. Asamblea de los cuerpos. Santiago, Sangría. 2019. Impreso.

Domingo, Daniel. "No era paz, era silencio: el sonido en el paisaje sociosemiótico urbano del 'estallido social' chileno desde los estudios ECDM". Revista Árboles y Rizomas, vol. 2, no. 2, 2020, pp. 44-68. Recuperado de http://www.revistas.usach. cl/ojs/index.php/rizomas/article/view/4611/26003661. 11 de abril de 2021.

Eltit, Diamela y Rita Segato. "Pensar en presente: cuerpo, virus, feminismo, politicidad". Aisthesis, no. 69, 2021, pp. 447-462. https://doi.org/10.7764/69.21

Espinoza, Denisse. "El arte de resistencia: cinco colectivos que surgieron y persisten tras del estallido social". Palabra Pública, 2020. Recuperado de http://palabrapublica.uchile.cl/2020/12/03/ arte-de-resistencia-cinco-colectivos-que-surgieron-y-persisten-tras-el-estallido-social/

Flores, María Iris. “Activismo, arte político, feminismos y memoria”. Creando, accionando, incidiendo. Trabajadoras en el arte. Gestoras en red. Eds. Ángela Neria-Muñoz, Marisol Frugone y Rosa Angeli. Santiago, Gestoras en Red, 2018, pp. 78-82.

Follegati, Luna. "El constante aparecer del movimiento feminista. Reflexiones desde la contingencia". Mayo feminista: la rebelión contra el patriarcado. Ed. Faride Zerán. Santiago, LOM editores, 2018, pp. 77-97. Impreso.

Giunta, Andrea. Feminismo y arte latinoamericano: historias de artistas que emanciparon el cuerpo. Buenos Aires, Siglo XXI, 2019. Impreso.

Grau, Olga. “Un cardo en la mano”. Mayo feminista: la rebelión contra el patriarcado. Ed. Faride Zerán. Santiago, LOM editores, 2018, pp. 91-97. Impreso. 
Lamadrid, Silvia. "Todas somos feministas: desafíos a una sociedad neoliberal y conservadora". Revista Análisis del Año 2019, 2020, pp. 83-106. Recuperado de https://www.uchile.cl/documentos/revista-analisis-del-ano-2019-pdf_166564_0_2236. pdf

"La protesta feminista de la Yeguada Latinoamericana en la Cámara de Diputados". El Mostrador, 13 de diciembre de 2018. https:// www.elmostrador.cl/noticias/multimedia/2018/12/13/laprotesta-feminista-de-la-yeguada-latinoamericana-en-lacamara-de-diputados/

Linett, Cheril. "Proyecto Yeguada Latinoamericana. Performance y feminismo disidente". Cuadernos de teoría social, no. 12, 2020, pp. 86-106.

Miranda Leiva, Lucía y Beatriz Roque López. "El mayo estudiantil feminista de 2018 en la Pontificia Universidad Católica de Chile: 'La revolución feminista"'. Activismos feministas jóvenes: emergencias, actrices y luchas en América Latina. Ed. Marina Larrondo y Camila Ponce Lara, CLACSO, pp. 5978. Recuperado de http://biblioteca.clacso.edu.ar/clacso/ gt/20191202034521/Activismos-Feministas-Jovenes.pdf

Oyarzún, Kemy. "Mayo 2018: feminismos en clave colonial". Mayo feminista: la rebelión contra el patriarcado. Ed. Faride Zerán. Santiago, LOM editores, 2018, pp. 99-113. Impreso.

Pizarro, Gabriela. "Episodios inéditos del sumario por acoso sexual contra el profesor Carlos Carmona," https://www.ciperchile.cl/2018/05/25/los-episodios-desconocidos-de-la-acusacion-por-acoso-sexual-contra-el-profesor-carlos-carmona/ Consultado el 31 de octubre, 2021

Sheffield, Carole, J. "Sexual terrorism". Gender violence. Interdisciplinary perspectives. Eds. Laura L. O’Toole, Jessica R. Schiffman y Margie L. Kiter Edwards. Nueva York, New York University Press, 2007, pp. 111-119. Impreso. 